\title{
Representações sociais de lei, justiça e injustiça: uma pesquisa com jovens argentinos e brasileiros utilizando a técnica de evocação livre de palavras ${ }^{1}$
}

\author{
Alessandra de Morais Shimizu \\ Maria Suzana De Stefano Menin \\ Universidade Estadual Paulista, Presidente Prudente
}

\begin{abstract}
Resumo
Este estudo teve como objetivo analisar as principais representações sociais de lei, justiça e injustiça apresentadas por jovens argentinos e brasileiros. O grupo de brasileiros constituiu-se de 621 pesquisandos, de três regiões distintas: Floriano/PI, Erechim/RS e Marília/SP. Da Argentina, participaram 200 jovens da cidade de Avellaneda (região metropolitana de Buenos Aires). Os grupos foram proporcionalmente divididos conforme o tipo de escola (pública e particular) e o ano escolar freqüentado ( $8^{\underline{o}}$ ano do Ensino Fundamental e $3^{\underline{0}}$ ano do Ensino Médio, considerando-se os graus equivalentes na Argentina). O instrumento de coleta de dados constituiu-se de um questionário semidirigido, composto pela técnica de evocação livre de palavras. O procedimento utilizado para a avaliação dos resultados foi a Análise de Correspondência (ANACOR). Os resultados demonstraram variações importantes relacionadas à nacionalidade dos jovens e foram discutidos de forma a contextualizarem-se as representações apresentadas.
\end{abstract}

Palavras-chave: teoria das representações sociais; evocação livre de palavras; lei; justiça.

\begin{abstract}
Social representations of law, justice and injustice: a research with Argentinean and Brazilian youngsters using the free evocation of words technique. This study aims to analyze the main social representations of law, justice and injustice presented by Argentinean and Brazilian youngsters. The Brazilian group consisted of 621 polled of three different regions: Floriano/PI, Erechim/RS and Marília/SP. From Argentina, 200 youngsters of Avellaneda city (Buenos Aires metropolitan region) participated. The groups were proportionally divided according to the kind of school (public or private) and the school year attended $\left(8^{\text {th }}\right.$ grade and $11^{\text {th }}$ grade, considering the equivalent grade in Argentina). The data collection technique consisted of semi directed questionnaire composed by the free evocation of words technique. The procedure used to evaluate the results was the Correspondence Analysis (ANACOR). The results demonstrated important variations related to the youngsters' nationality and they were discussed so that the presented representations were contextualized.

Keywords: social representations theory; free evocation of words; law; justice.
\end{abstract}

$\mathrm{E}$ ste estudo teve como objetivo pesquisar as associações realizadas por jovens argentinos e brasileiros em relação às palavras lei, justiça e injustiça, a fim de analisá-las segundo a Teoria das Representações Sociais.

Atualmente a Teoria das Representações Sociais tem ocupado um espaço importante no meio científico, sendo muito utilizada para a interpretação dos fenômenos sociais. A noção de representação social foi introduzida na Psicologia Social pelo francês Serge Moscovici em 1961, com a obra A Psicanálise, sua imagem e seu público.

Ao pesquisar como se dava a implantação da Psicanálise na vida cotidiana da população parisiense no final da década de 50, passando do domínio acadêmico para o senso comum, Moscovici (1978) comprovou que uma teoria científica pode estar mais próxima dos indivíduos do que se imagina. A partir dessa proximidade encontrada entre a ciência e os indivíduos, o pesquisador pressupôs o potencial de uma abordagem científica em transformar a existência humana, não só no que tange às consequiências objetivas de sua aplicabilidade ou influências que exerce sobre outra teoria, mas principalmente pela apropriação que os indivíduos dela fazem, transportando-a para o universo das relações sociais, dentro do qual passa a fazer parte integrante das falas, gestos, costumes, emoções e pensamentos de cada indivíduo e, ao mesmo tempo, de todos. 
As representações sociais são concebidas por Moscovici (1978) como fenômenos psicossociológicos, podendo ser explicadas com base em implicações não só psicológicas como também sociais e ideológicas, o que as integra ao contexto das determinações históricas e culturais. A cultura, as trocas simbólicas, o processo de construção e reconstrução do cotidiano, conduzem cada indivíduo à organização de uma realidade que tem como base um imaginário coletivo, diverso em cada tempo e espaço, que se transforma em um imaginário individual - sem deixar, no entanto, de ser uma expressão do que é coletivo.

Esse imaginário constitui-se em um conhecimento construído que irá reger a forma como os indivíduos representam o mundo e conduzem suas ações. Cada indivíduo constrói e utiliza uma representação social de um objeto possivelmente relacionada com o grupo social ao qual ele pertence. Isso leva a crer que as representações sociais se diferenciem conforme os conjuntos sociais dentro dos quais elas se elaboram.

A partir da teoria de Moscovici (1978), novas áreas de investigação e diferentes maneiras de se conceber a elaboração das representações sociais têm sido desenvolvidas.

Considerando-se nosso especial interesse em avaliar o papel que os fatores sócio-culturais possam exercer sobre a formação das representações sociais de lei, justiça e injustiça, continuaremos nossos estudos aprofundando-nos em relação à proposta teórica apresentada por Doise $(1990 ; 1993)$, uma vez que esse autor aborda mais especificamente a dimensão das condições de produção e circulação das representações sociais.

\section{A noção de representação social segundo Willem Doise}

Segundo Doise (1990; 1993), um dos principais fatores determinantes na formação das representações sociais é a posição ou inserção social dos indivíduos e grupos. Baseado nesse entrelaçamento entre as dinâmicas relacionais e as representativas, define as representações sociais como "princípios geradores de tomadas de posição ligados às inserções específicas em um conjunto de relações sociais, e que organizam os processos simbólicos intervenientes nessas relações" (Doise, 1986, p.85).

Em sua obra, Lógicas sociais no raciocínio (1993), o pesquisador procura demonstrar como os modelos cognitivos não conceituam explicitamente a intervenção das dinâmicas sociais, devido ao fato de serem insuficientes na explicação da atividade de raciocínio do indivíduo. Assim, propõe-se a estudar as condições sociais que intervêm diretamente no raciocínio sobre os diferentes aspectos da realidade social.

Doise (1993) privilegia a intervenção das dinâmicas sociais, assim como a de natureza cultural, nas atividades cognitivas de raciocínio. Com esse propósito, afirma que podem ser realizados quatro diferentes níveis explicativos na Psicologia Social: (1) nível intrapessoal, no qual é focalizada apenas a maneira como o indivíduo organiza sua experiência no ambiente, não oferecendo explicações sociais e/ou a respeito da interação do indivíduo com o meio em que está inserido; (2) nível interpessoal e situacional, que tem como princípios explicativos típicos os sistemas de interação, uma vez que os indivíduos são considerados como intercambiáveis e as operações cognitivas são estudadas por coordenações interindividuais ou mediante a confrontação de diferentes perspectivas; (3) nível posicional, que leva em conta as mais diversas posições que os diferentes atores sociais ocupam no emaranhado das relações sociais características de uma sociedade; e (4) nível ideológico, que enfoca os sistemas de crenças, representação, avaliações e normas sociais que toda sociedade desenvolve para fins de validação e manutenção da ordem social estabelecida. Ainda segundo Doise (1993), são as produções culturais e ideológicas características de uma sociedade ou de certos grupos particulares que dão significado aos comportamentos individuais e criam ou mantêm as diferenciações sociais em nome de princípios gerais.

Essa distinção entre os quatro níveis, no entanto, não deve ter somente objetivos classificatórios, mas deve, sobretudo, servir para um trabalho articulado de análise.

Já existem alguns trabalhos, nacionais e internacionais, guiados pelas representações sociais, que investigam temas comuns à nossa pesquisa. Dentre os pesquisadores internacionais, podem-se destacar os próprios estudos de Doise e outros (Doise \& Clémence, 1996; Doise, Clémence, De Rosa, \& Gonzalez, 1995; Doise, Dell Ambragio, \& Spini, 1991; Doise \& Herrera, 1994), os quais procuram explorar e entender os limites da universalidade dos direitos humanos e de suas representações sociais em relação a diversidades culturais e contextos sociais específicos; a investigação de PierrePuysegur e Corroyer (1987) a respeito das representações sociais do sistema penal em crianças francesas; o estudo de Emler e Ohana (1992) sobre as representações sociais de crianças em relação a situações de danos ou prejuízos intencionais e, finalmente, a pesquisa de Halman (1995) sobre os sistemas de valores e a orientação moral de jovens e adultos de diferentes países, na qual o autor procurou analisar o efeito dos sistemas políticos e econômicos e a incidência da idade e educação sobre os valores morais.

Entre os estudos brasileiros, pode-se apontar a pesquisa de Camino, Moraes, Pereira e Cruz (2000) sobre as representações de jovens universitários em relação a duas proposições da Declaração Universal dos Direitos Humanos: a primeira, proclamada pelo Artigo $1^{\underline{o}}$, que discorre sobre o direito fundamental de liberdade e igualdade entre os homens, e a segunda, referente ao Artigo 29, sobre o dever de respeitar os direitos dos outros; os estudos sobre justiça orientados por Assmar (2000), que buscam avaliar de forma mais completa o fenômeno em questão, procurando identificar os níveis de análise propostos por Doise (intraindividual, interpessoal, posicional e ideológico); e a pesquisa de Menin (2001) sobre as representações sociais de lei, crime e injustiça, realizada com adolescentes de diferentes níveis socioeconômicos, da cidade de Presidente Prudente, São Paulo. É esse mesmo caminho que procuramos seguir em nosso trabalho. 


\section{Método}

\section{Participantes}

Os participantes da pesquisa foram 621 jovens brasileiros e 200 jovens argentinos.

O grupo brasileiro foi distribuído conforme a região de procedência, o tipo de escola (pública e particular) e o ano escolar freqüentado, da seguinte maneira: (a) 241 jovens de Erechim (RS), sendo 58 do $8^{\underline{0}}$ ano do Ensino Fundamental de escola pública, 63 do $8^{\circ}$ ano do Ensino Fundamental de escola privada, 59 do $3^{\underline{o}}$ ano do Ensino Médio de escola pública e 61 do $3^{\circ}$ ano do Ensino Médio de escola privada; (b) 209 jovens de Floriano (PI), sendo 54 do $8^{\underline{o}}$ ano do Ensino Fundamental de escola pública, 54 do $8^{\underline{0}}$ ano do Ensino Fundamental de escola privada, 54 do $3^{\underline{0}}$ ano do Ensino Médio de escola pública e 47 do $3^{\circ}$ ano do Ensino Médio de escola privada; e (c) 171 jovens de Marília (SP), sendo 50 do $8^{\mathrm{O}}$ ano do Ensino Fundamental de escola pública, 41 do $8^{\underline{0}}$ ano do Ensino Fundamental de escola privada, 52 do $3^{\underline{0}}$ ano do Ensino Médio de escola pública e 28 do $3^{\underline{0}}$ ano do Ensino Médio de escola privada.

Os 200 participantes argentinos, provenientes de Avellaneda, região metropolitana de Buenos Aires, foram igualmente distribuídos conforme o tipo de escola (pública e particular) e o ano escolar freqüentado, da seguinte maneira: 50 alunos do $9^{\underline{0}}$ grau do Ensino Primário de escola pública, 50 do $9^{\circ}$ grau do Ensino Primário de escola privada, 50 do $13^{\circ}$ grau do Ensino Secundário de escola pública e 50 do $13^{\circ}$ grau do Ensino Secundário de escola pública.

Descreveremos as principais características dos participantes de forma sucinta e geral, pautadas em resultados numéricos e testes estatísticos que não serão apresentados neste artigo para que não o estendamos em demasia.

Em relação à faixa etária dos jovens brasileiros e argentinos, encontramos em ambos os grupos duas faixas predominantes, de 13 a 14 anos e de 16 a 17 anos, marcadas pelos anos escolares que os jovens freqüentavam (respectivamente $8^{\underline{o}}$ ano do Ensino Fundamental e $3^{\underline{o}}$ ano do Ensino Médio). No que diz respeito ao sexo dos participantes, observamos uma distribuição mais proporcional entre indivíduos masculinos e femininos no grupo argentino; enquanto neste a distribuição foi quase precisamente equivalente (apresentando uma diferença de apenas $0,5 \%$ mais homens do que mulheres), no grupo brasileiro essa diferença foi de $21 \%$ (mais mulheres do que homens).

No que tange à preferência religiosa, observamos que a maioria dos brasileiros e argentinos se designa católica; no entanto, é muito maior o número de católicos não-praticantes entre os argentinos que entre os brasileiros. Além disso, encontramos um número significativamente maior de jovens sem religião no grupo argentino.

Comparando o status socioeconômico dos dois grupos, verificamos, mediante significância comprovada pelo teste qui-quadrado $(p=0,01)$, que os jovens argentinos apresentam um melhor nível socioeconômico que os brasileiros, devido a uma maior escolarização e melhor posicionamento pro- fissional dos pais (não podemos nos esquecer do período em que esta pesquisa foi realizada na Argentina: outubro e novembro de 2001, fase em que a crise econômica Argentina iniciava sua intensificação). Além disso, constatamos que o grupo brasileiro é economicamente mais heterogêneo que o argentino, uma vez que sua desigualdade de nível de escolaridade e status profissional entre os pais de participantes de escolas públicas e os de escolas particulares é bem maior.

\section{Coleta e análise dos dados: a técnica de evocação livre}

$\mathrm{O}$ instrumento de pesquisa que descreveremos a seguir foi aplicado aos jovens em sala de aula. As aplicações foram autorizadas formalmente pela direção de cada escola participante e consentidas livremente pelos pesquisados. Tanto os objetivos deste estudo como sua relevância social foram explicitados previamente. Foi assegurada também, a cada participante, a não divulgação, sob quaisquer circunstâncias, de sua identidade para outras pessoas ou entidades. A coleta de dados foi realizada, no Brasil, no decorrer do ano de 2000 e, na Argentina, nos meses de outubro e novembro de 2001. O instrumento de coleta de dados utilizado foi um questionário semi-dirigido construído com base na Teoria das Representações Sociais. Entre outras questões - às quais não nos reportaremos no presente artigo -, abordaram-se as principais representações dos indivíduos frente às palavras-estímulo: lei, justiça e injustiça. Utilizou-se, para esse fim, a técnica da evocação livre de palavras, que consiste na apresentação de uma palavra-estímulo ao respondente para que ele, por meio da associação livre, designasse o objeto apresentado. Com base em Zonta (1997), solicitamos aos participantes da pesquisa que respondessem quatro palavras para cada uma das três palavras-tema eliciadoras.

O procedimento utilizado para a análise dos dados coletados pela técnica de evocação livre de palavras foi fundamentado em Zonta (1997). Inicialmente digitamos as quatro palavras evocadas por cada participante após a apresentação de cada palavra-estímulo, em um editor de texto em formato "texto simples" (txt). Em seguida, processamos os arquivos prontos - um arquivo de cada país de origem e para cada palavra-estímulo - no software francês SPADT (Système Portable pour l'Analyse des Donnés Textuelles) e obtivemos, para cada um deles, duas listagens de distribuição das palavras evocadas: uma por ordem alfabética e outra por ordem de frequiência. Com base nessas listagens, efetuamos a homogeneização das palavras sinônimas, substituindo as de menor ocorrência pelas de maior ocorrência. Nesse trabalho, procuramos ser o mais cautelosas possível, a fim de sempre preservar o sentido representacional da palavra substituída.

Depois de realizada a homogeneização das palavras, processamos novamente os arquivos no SPADT e obtivemos as listagens finais das palavras evocadas por ordem de freqüência. Selecionamos então as palavras mais citadas, seguindo como critério uma porcentagem mínima de $2 \%$ em relação ao grupo total - no grupo brasileiro a incidência mínima foi de treze para cada palavra, e no argentino, de quatro. 
Entre os vocábulos evocados selecionamos, para todas as palavras-estímulo, os dez mais freqüentes para que fossem, então, analisados por Análise de Correspondência (ANACOR). Em seguida, transformamos os arquivos de texto simples (txt) em arquivos do software SPSS (Statistical Package for the Social Sciences) e cruzamos as dez palavras mais frequientes geradas por cada palavra-estímulo com elas mesmas, construindo um banco de dados indicativo das freqüências dos cruzamentos entre os vocábulos. Por exemplo: consideremos que no arquivo relativo à palavra-estímulo lei, do grupo brasileiro, o cruzamento da palavra dever com a palavra ordem foi de 30 vezes. Isso significa que entre os 621 jovens brasileiros entrevistados, 30 deles associaram a palavra-estímulo lei com ambas as palavras dever e ordem.

Após registrarmos as freqüências desses cruzamentos, construímos um novo banco de dados que, depois de ser processado no SPSS, resultou em uma matriz simétrica relativa à freqüência dos cruzamentos de todas as palavras evocadas com elas mesmas. Conforme Zonta (1997), essa matriz é demonstrativa do grau de relação de cada uma das nove palavras mais freqüentes com elas mesmas - foram nove e não dez, porque uma das regras estatísticas do procedimento ANACOR é a eliminação do último vocábulo, para a construção da matriz simétrica. Essa matriz indica, assim, a proximidade do espaço semântico destas palavras, de forma que os vocábulos com maior ocorrência de associação entre si devem ser concebidas como sendo próximas no que diz respeito às suas correspondências semânticas em relação à palavra-estímulo. No entanto, Zonta (1997) esclarece que, embora as freqüências desses cruzamentos possam revelar conteúdos representacionais, não são suficientes para analisarem-se seus perfis no conjunto dos participantes de cada grupo estudado.
Com base nisso, continuamos o procedimento elevando ao quadrado os resultados dessa matriz simétrica para que obtivéssemos uma matriz euclidiana possibilitando então a análise dos dados de todas as palavras cruzadas, mesmo quando o resultado do cruzamento de determinada palavra com outra fosse igual a zero.

Dessa forma, foi-nos possível construir, para cada palavra-estímulo, um gráfico scatterplot demonstrativo dos resultados dos cruzamentos das palavras. Conforme Zonta (1997), por meio desse gráfico é possível analisar o espaço semântico do campo representacional de cada população estudada em relação à palavra-estímulo apresentada. A posição central do gráfico corresponde à palavra-estímulo, ou seja, esta se localiza no cruzamento do eixo da abscissa (X) com o eixo da ordenada (Y) sobre o ponto zero (em $0 ; 0$ ), indicado em nosso estudo por um asterisco (*). Quanto mais próxima do centro se localiza uma palavra associada, mais freqüente é a associação desta com a palavra-estímulo. É possível, então, considerar-se sua representação como mais consistente, assim como se indicarem os possíveis sentidos circunscritos nas relações que se apresentam.

\section{Resultados}

\section{Associações dos jovens brasileiros e argentinos às} palavras: lei, Justiça e Injustiça

Iniciando a análise das associações dos jovens, verificamos na Figura 1, referente às associações dos jovens brasileiros à palavra lei, um agrupamento, na parte central do gráfico, constituído pelos vocábulos importante, ordem, obrigação, respeito, cumprir e dever. Logo acima deste subgrupo está o vocábulo regra e, abaixo, justiça. No quadrante direito superior do gráfico localiza-se a palavra injustiça e no inferior, justiça.

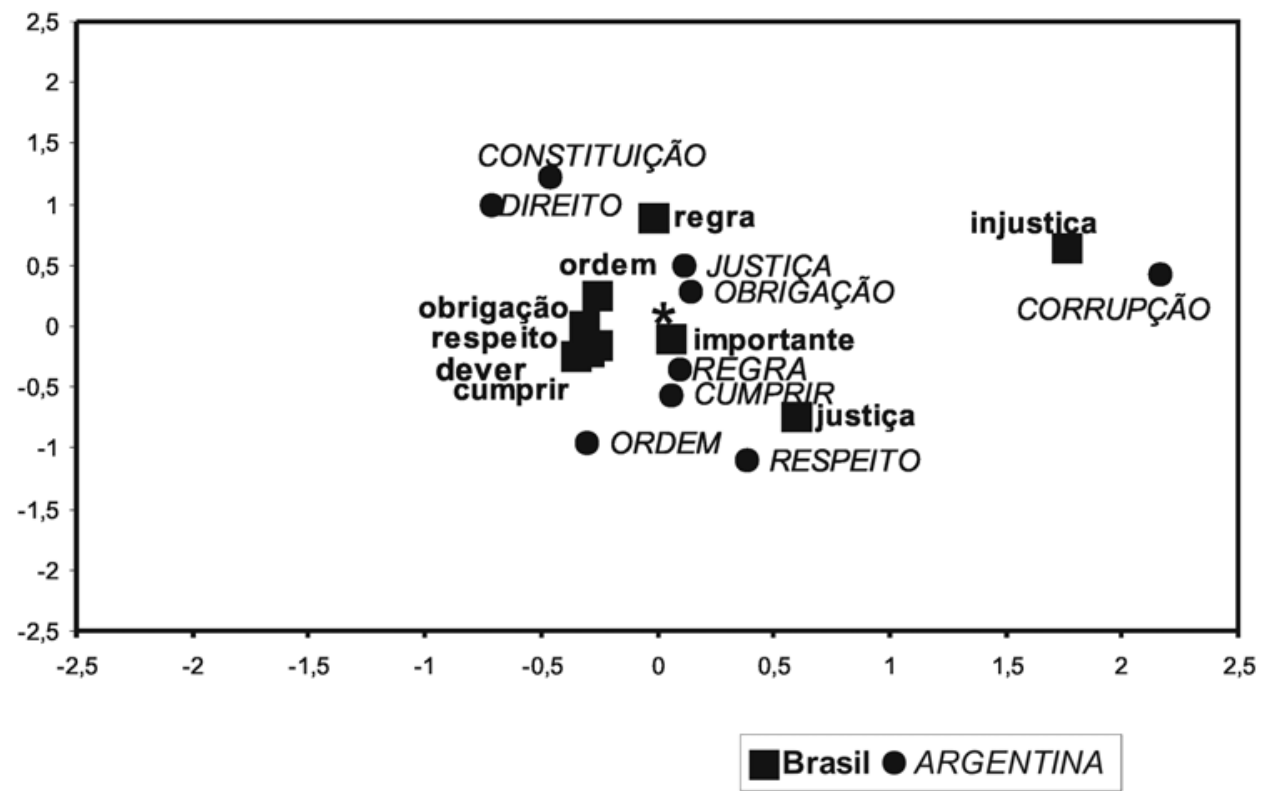

Figura 1. Gráfico de ANACOR demonstrativo do campo representacional de respondentes brasileiros e argentinos em relação à palavra-estímulo lei. 
Esses dados sugerem que, para os jovens brasileiros, a lei é muito importante, sendo necessária para o estabelecimento da ordem social. É também uma obrigação e dever de todos que ela seja respeitada e cumprida. Associado à palavra ordem está o vocábulo regras, o que indica seu pertencimento, também, a esse mesmo campo representacional. Além disso, a lei é aplicada pela justiça quando consideramos esta palavra no sentido institucional. No entanto, apesar de às vezes a lei fazer justiça, quando a compreendemos em seu caráter moral também é capaz de provocar injustiças.

Em relação ao grupo argentino observamos, no centro do gráfico da Figura 1, a formação de um primeiro subgrupo, formado pelas palavras justiça e obrigação. Logo abaixo, e bem próximo deste subgrupo, está o agrupamento das palavras regra, cumprir, ordem e respeito. Acima do subgrupo central encontramos os vocábulos constituição e direito. Dispersa em relação às demais palavras do gráfico, localizase corrupção (quadrante direito superior). Assim, para os jovens argentinos, a lei é uma obrigação da justiça, no sentido institucional, e tem a obrigação de fazer justiça, no sentido moral. São regras que devem ser cumpridas e respeitadas para a conservação e a preservação da estabilidade da ordem social. É, também, um direito constitucional de todos, garantindo, por meio da constituição, que todos tenham os seus direitos preservados. No entanto, essa lei, que tem a obrigação de fazer justiça, e que é um direito constitucional, está associada à corrupção, porém de forma não tão consensual.

Em relação às associações à palavra justiça realizadas pelos jovens brasileiros, conforme é possível verificar-se no gráfico da Figura 2, as palavras direito e lei estão posicionadas bem próximas ao eixo central possuindo, portanto, maior for- ça representacional. Mais acima se encontram as palavras respeito e igualdade. No quadrante superior direito localizam-se os vocábulos desigualdade e falta. No quadrante inferior do gráfico estão as palavras julgamento, relativamente próxima ao subgrupo posicionado no eixo central, certo e depois necessária, posicionadas de forma mais dispersa que as demais.

Como se pode visualizar nessa figura, para os respondentes brasileiros a justiça é, sobretudo, um direito que deve ser garantido pela lei. O julgamento representa a forma institucional mediante a qual ela cumpre seu papel. Ela deve fazer o que é certo e, portanto, é necessária. A justiça também está relacionada com respeito e igualdade; porém, não existe um consenso em relação ao que essas duas palavras representam, visto encontrarem-se um pouco mais afastadas do centro do gráfico - o que sugere não estarem tão fortemente associadas às palavras direito e lei, apesar de existir uma correspondência entre elas.

Com base nisso, podemos sugerir que essa representação possui dois sentidos. O primeiro é o de que a justiça, enquanto instituição, deveria garantir pela lei o respeito à igualdade de direitos. Além disso, fazer justiça implica, no sentido moral, respeitar e tratar todos com igualdade. De qualquer forma, no primeiro ou no segundo sentido que se dê à justiça, nem sempre ela é garantida, visto que, mesmo não tão consensualmente, mas pertencendo a esse campo representacional, estão no quadrante direito superior do gráfico, e próximas entre si, as palavras falta e desigualdade.

Para os argentinos, no entanto, como se pode observar na Figura 2, a palavra justiça relaciona-se estreitamente a juiz, posicionada bem próxima ao eixo central do gráfico, o que indica sua representação no sentido institucional. A justiça tem, dessa forma, como seu maior representante o juiz,

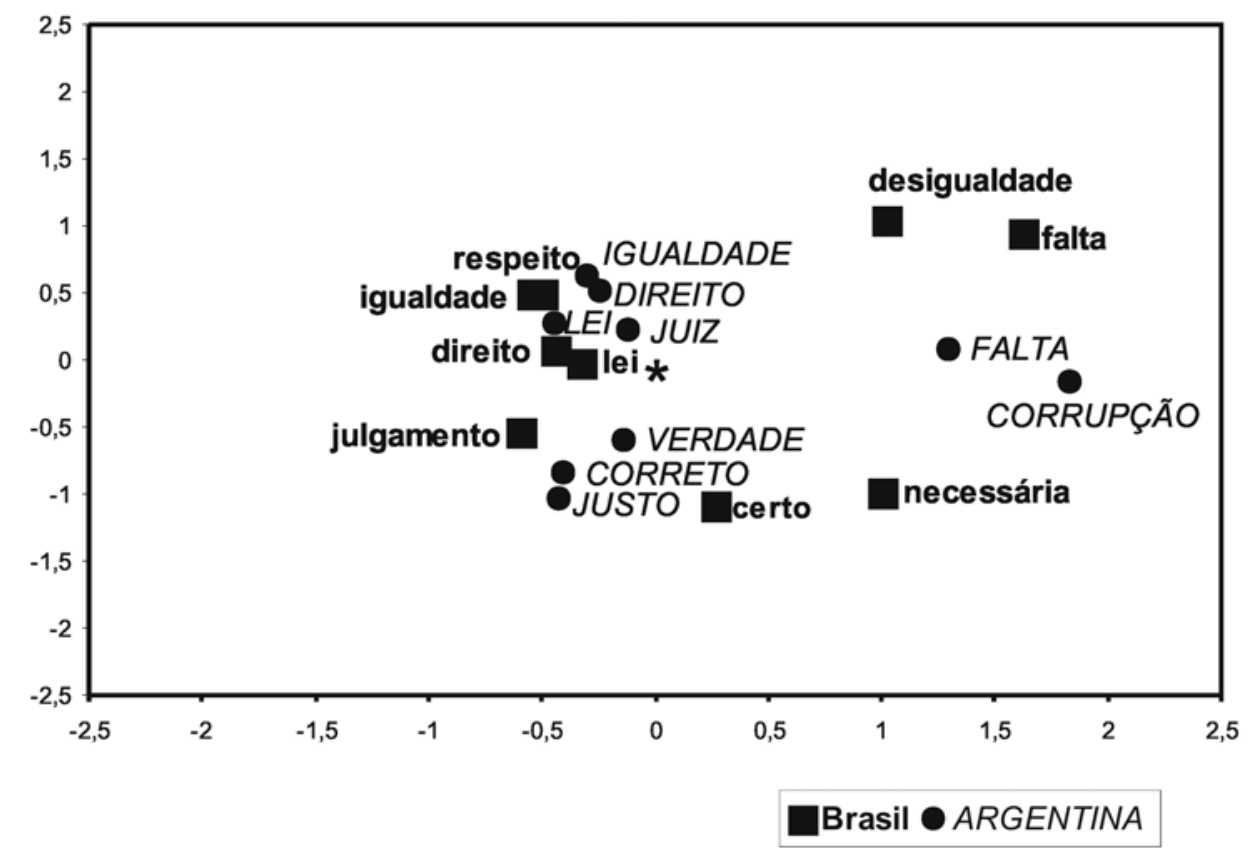

Figura 2. Gráfico de ANACOR demonstrativo do campo representacional de respondentes brasileiros e argentinos em relação à palavra-estímulo justiça. 
que pela lei garante a igualdade de direitos (palavras que compõem o subgrupo mais próximo à palavra juiz). As palavras verdade, correto e justo também estão associadas a justiça, posicionadas abaixo do eixo central, com uma proximidade considerável deste. Observamos que os jovens evocam também as palavras falta e corrupção, com uma associação importante entre ambas.

Em relação ao sentido dado pelo grupo brasileiro à palavra injustiça, representado na Figura 3, notamos o posicionamento das palavras desigualdade, corrupção e preconceito bem próximo ao eixo central, indicando a existência de um forte consenso entre os jovens brasileiros de que injustiça é a desigualdade, a corrupção e o preconceito. Em seguida estão posicionados, no quadrante inferior do gráfico, os vocábulos crime e pobreza que, igualmente, representam a injustiça. No quadrante superior do gráfico estão os vocábulos desrespeito, errado, tristeza e, mais distante, realidade.

Quanto às associações do grupo argentino em relação a essa mesma palavra-estímulo (ainda na Figura 3), notamos que no quadrante inferior do gráfico temos o subgrupo das palavras mentira, corrupção, desigualdade, imoral e crime. Para os jovens argentinos, portanto, injustiça é a mentira e a corrupção, que estão associadas à desigualdade, ao crime e à imoralidade. No quadrante superior do gráfico encontramse as palavras mal, incorreto, realidade e políticos, indicando que a injustiça faz muito mal para a sociedade e é incorreta, estando relacionada com a realidade política do país.

\section{Discussão}

Comparando as representações de lei, justiça e injustiça entre os grupos do Brasil e da Argentina, notamos que, devido ao fato de se tratar de estruturas simbólicas organizadas em espaços semânticos, dão expressão aos aspectos intrínsecos da vida cotidiana, revelando características peculiares de seus personagens que são marcados pela história de cada povo, sua cultura e pelo modo de se relacionarem com a realidade vivida.

Em relação à lei, constatamos que, apesar de ser comum entre os jovens de ambos os países a representação de que esta é necessária para o estabelecimento e a manutenção da ordem social, os brasileiros dão uma maior ênfase a essa função. Para estes, a lei é carregada de um caráter impositivo, o que se comprova, também, mediante a estreita relação apresentada entre as palavras ordem, obrigação, cumprir e dever. $\mathrm{Ou}$ seja, é um dever de todos que a lei seja cumprida e, assim, a ordem se estabeleça. Para os jovens argentinos, por sua vez, são os sistemas responsáveis pela lei que têm como obrigação garantir a justiça. No entanto, a justiça garantida pela lei não se restringe somente à preservação da ordem e ao cumprimento e respeito às suas regras: vista em um sentido muito mais amplo, é considerada um direito constitucional e, como tal, deve assegurar os direitos de todos, prescritos pela Constituição.

Apesar dessas diferenças, notamos que tanto os jovens argentinos como os brasileiros possuem uma desconfiança em relação à lei, vendo-a com um olhar crítico. Mas, enquanto

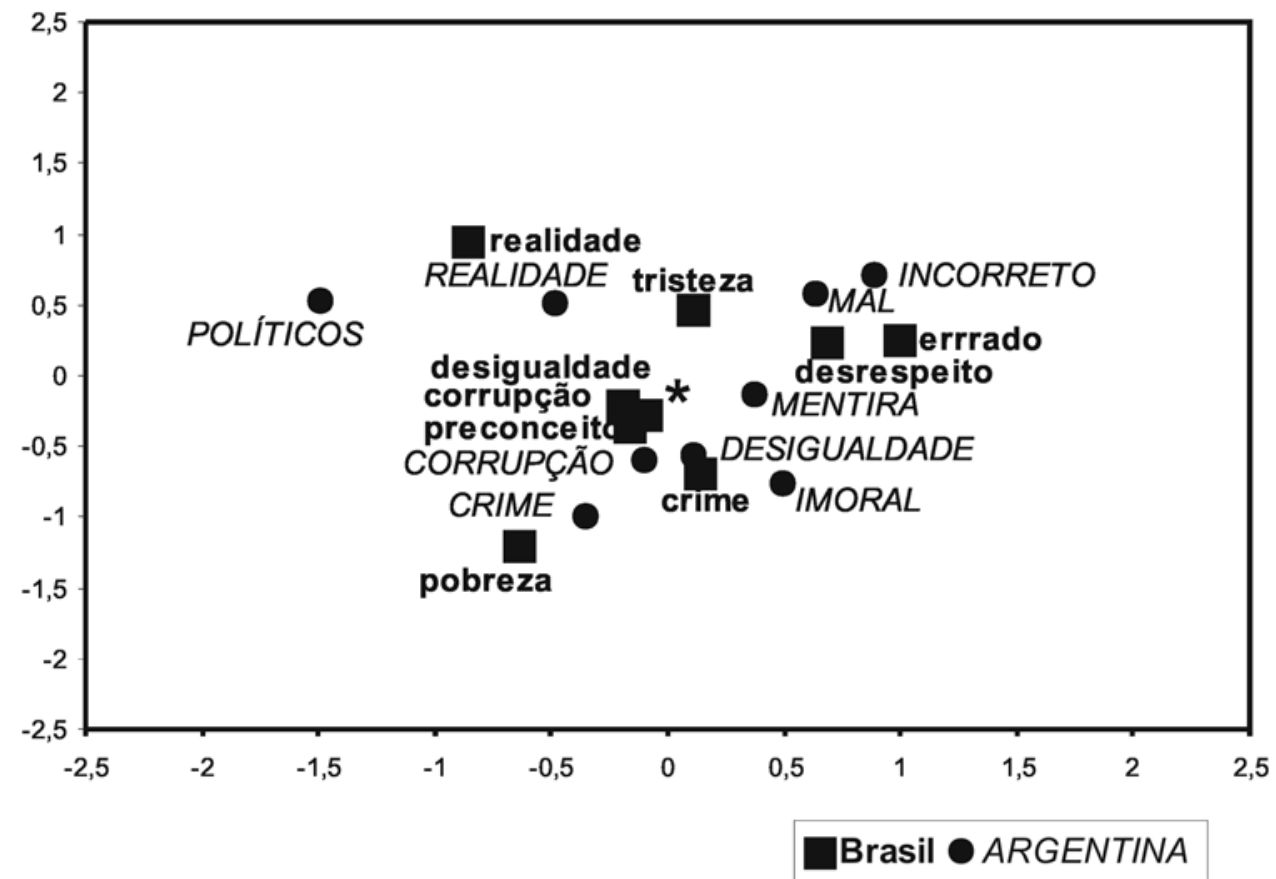

Figura 3. Gráfico de ANACOR demonstrativo do campo representacional de respondentes brasileiros e argentinos em relação à palavra-estímulo injustiça. 
os brasileiros expressam o resultado negativo da lei quando não cumprida adequadamente - a injustiça -, os argentinos expressam o motivo pelo qual a justiça não cumpre sua obrigação legal - a corrupção.

Dessa maneira, enquanto os jovens brasileiros demonstram um menor esclarecimento em relação às leis e, conseqüentemente, um maior distanciamento e uma postura mais submissa, passiva e fatalista em relação a elas, os argentinos mostram-se mais conscientes do papel das leis na sociedade, conhecendo melhor suas atribuições, seu funcionamento e as possíveis causas de seu "não funcionamento".

A justiça, por sua vez, é representada pelos jovens de ambos os países, sobretudo no sentido institucional, sob a idéia de que o que é justo é o que é legal, e de que a justiça é feita pelos representantes do sistema judiciário (juiz e julgamento). Nesse contexto representacional, a justiça é concebida como um direito que garante o princípio de igualdade na aplicação da lei, e esse sentido tem uma força representacional maior entre os jovens da Argentina, uma vez que, enquanto as palavras lei, direito e igualdade estão bem próximas para o grupo daquele país, entre os brasileiros a proximidade maior ocorre primeiramente entre as palavras lei e direito e, em seguida, entre os vocábulos igualdade e respeito - o que carrega a palavra igualdade de um duplo sentido, moral e/ou legal. Observamos, então, que enquanto para os jovens brasileiros o direito está em ter a lei para garantir essa igualdade, seja moral ou legal, para os argentinos está explícito que a justiça deve garantir, por meio da lei, não só o direito à igualdade, como também a igualdade de direitos.

Em ambos os países também fica explícita, assim como em relação à lei, a existência de uma certa desconfiança e insatisfação em relação à justiça com a qual os jovens estão familiarizados, pois "falta justiça". Novamente, no entanto, a forma como essa desconfiança é representada pelos brasileiros é diferente do modo como os argentinos o fazem: enquanto os primeiros enfatizam o resultado negativo que essa falta gera (a desigualdade), os últimos apontam o motivo pelo qual ela falta (a corrupção).

No que diz respeito à palavra-estímulo injustiça, verificamos que as representações construídas pelos brasileiros se referem ao sentido social da palavra - o que, talvez, esteja mais aparente em nossa sociedade. Representando-as com base no contexto da realidade social, os jovens descrevem a injustiça na forma da desigualdade, corrupção e preconceito e revelam as suas conseqüências: o crime e a pobreza; constróem um julgamento de valor em relação a essa realidade ao afirmarem que é errada e que é um desrespeito. Demonstram sentirem-se amarrados em relação a esse contexto, ao expressarem que essa é uma "realidade triste".

Os jovens argentinos, de outro modo, dão maior ênfase às causas da injustiça que às suas conseqüências: a realidade política do país, a mentira e a corrupção que levam à desigualdade, a qual gera o crime. O julgamento de valor construído em relação à injustiça é de que ela é sobretudo imoral, faz mal e é incorreta.

\section{Considerações finais}

Interpretamos as representações encontradas nesta pesquisa como reveladores de como os jovens investigados se apropriam, dão sentido e redefinem as condições sociais e históricas que marcam o contexto no qual estão inseridos. Realizaremos essas considerações finais enfocando especialmente a realidade brasileira, e pautados em autores que buscam, em seus estudos, compreender alguns aspectos relativos ao funcionamento da nossa sociedade.

A noção de cidadania no Brasil, segundo Da Matta (1987, 1991), perdeu seu sentido político universal e nivelador. Formalmente, ela está inserida no ideário ético-político, descrito nos comícios políticos como metas prioritárias dos programas de partidos e plataformas eleitorais; ou então, está presente nas Constituições, as quais defendem que todos devem ser iguais perante a lei, a qual deve garantir seus direitos. Informalmente e na prática social, no entanto, a cidadania não é vivida dessa maneira. Existe um jogo duplo na política brasileira, em que o discurso público se refere aos direitos e necessidades dos cidadãos do país, de uma nação regida e fundada em seus cidadãos; porém, o que impulsiona o cotidiano da sociedade é uma prática política que se rege pela lealdade das relações pessoais, desvinculada de qualquer compromisso legal ou ideológico. Essa realidade não passa despercebida pela população brasileira, que vê de tudo na atividade política, menos a ética.

Conforme Souza (1999), a construção das leis brasileiras foi marcada por um contexto paradoxal: de um lado, foi inspirada em um projeto de instalação de um liberalismo nacional e, de outro, padeceu pela ausência de legitimidade e por sua condição de alienada em relação às necessidades intrínsecas às experiências das relações cotidianas. Essa distância entre a lei e a população resultou não só na falta de representatividade do povo na lei, como também no não reconhecimento da própria elite autora da lei no código formal. Essa lacuna entre a lei escrita e a necessidade da lei na prática foi sendo preenchida, então, pelas leis informais, as quais, por sua vez, poderiam dar margens a duas formas distintas de relacionamento com a lei: uma ética, que possibilitasse maior igualdade e autonomia aos sujeitos sociais e outra, que levaria à aceitação da lei pautada em sua plausibilidade de ser ludibriada.

No entanto, predominando a segunda forma de uso da lei informal, esta passou a ser (situação que, muitas vezes, ainda perdura em nossos dias) um privilégio da elite. Embora os crimes ocorram nos mais diversos estratos sociais, os possuidores de poder econômico e político têm maior chance de burlar a lei e saírem incólumes. Dessa maneira, dá-se a essa parcela da população, especialmente, condições de escolher entre o uso ou não do código formal, da maneira e no momento que melhor lhe convém e, por extensão, o acesso a privilégios sociais e econômicos - os quais, entre outras regalias, podem lhes garantir o escudo da impunidade, fechando o círculo vicioso. 
As diferentes formas de se representar a lei e se relacionar com ela são determinadas, portanto, pelo posicionamento socioeconômico dos sujeitos e pela maneira como suas necessidades são atendidas no contexto social.

Jovchelovitch (2000) descreve a relação entre as esferas pública e privada no Brasil e suas repercussões no funcionamento contextual brasileiro. De acordo com a pesquisadora, é fundamental que existam demarcações nítidas de fronteiras entre as esferas pública e privada e, ao mesmo tempo, uma relação dialética essencial entre ambas, na qual se sustente a possibilidade de democracia e exercício da cidadania. Apenas a existência dessa interação pode levar os sujeitos políticos a utilizarem a ação e o discurso em função da esfera da vida que é comum a todos, sem se voltarem apenas para interesses privados e intimidades.

A mesma autora aponta, porém, a existência de um desequilíbrio entre a vida pública e a privada, no qual se perdeu parte fundamental da vida do indivíduo fora do círculo familiar, o que torna os outros seres humanos estranhos ou ameaçadores. Dessa forma, o silêncio substituiu a conversa e a observação tomou o lugar da participação como única maneira pela qual se experiencia a vida pública; ao mundo público sobrepõe-se a prioridade de um psiquismo privado que conduz à degeneração do indivíduo e da sociedade.

Em pesquisa sobre as representações dos brasileiros sobre a vida pública, Jovchelovitch (2000) constatou que seu principal aspecto é a "corrupção". Essas representações, segundo a autora, baseiam-se nos eventos que têm marcado a vida política do Brasil, tanto no decorrer de nossa história como nos tempos atuais. A análise desses eventos, portanto, pode levar à compreensão dos mitos, afetos e imagens que constituem essas representações. $\mathrm{O}$ brasileiro crê que a política é uma realidade que foge do controle do cidadão, resultando, assim, "em uma vida política privada do povo e um povo privado de representantes na vida política" (p. 129).

Com base nessa experiência vivida e ouvida, os brasileiros acabam por conceber a corrupção como uma realidade imutável, devido à relação entre "poderosos" e "sem poder": em contrapartida à onipotência dos "poderosos", resta a impotência dos "sem poder". Esta conduz ao fatalismo e, curiosamente, a que se evite a autonomia.

Jovchelovicth (2000) acredita que, em meio à sua herança social e política, o Brasil ainda não foi competente o suficiente para desenvolver uma esfera pública sem limitações. Assim, nega ao seu povo o direito à cidadania, uma vez que está longe da realidade brasileira o reconhecimento da existência de um espaço público em que haja a garantia de um estado de direito, declarado em uma constituição e funcionando plenamente nas instituições sociais. Ainda formamos uma sociedade autoritária, na qual os direitos de poucos compõem a carência de muitos; a lei não é capaz de exercer sua função de proteger os direitos dos cidadãos e a cidadania ecoa como uma noção mais abstrata do que real.

O abismo existente entre um código constitucional explícito e escrito e um código de práticas implícito demonstra o quão insalubre se torna uma fusão entre o que é pessoal e o que é público. No Brasil, o que é público é questão pessoal, como produto de uma teia de relações que terminam por construir uma ordem pública em que preponderam os interesses pessoais e a ambivalência das leis, feitas por pessoas a quem elas nunca se aplicam.

As reflexões dos pesquisadores aos quais nos referimos acima, em relação à realidade social brasileira, não só contextualizam social e historicamente as representações apresentadas pelos jovens brasileiros averiguadas por nossa pesquisa, explicando em que condições foram erigidas, como também fazem referência aos tipos de estratégia de que os mesmos jovens têm de lançar mão para sobreviverem diante da realidade de nosso país, ou seja, frente a essa "grande rua que se chama Brasil".

Como afirmamos anteriormente, ao compararmos os jovens brasileiros com os argentinos, estes últimos demonstram estarem mais próximos dos aparatos legais, apresentando um melhor esclarecimento em relação a eles, assim como um poder de ação mais efetiva na esfera pública.

Entre os brasileiros, essa forma de relacionamento com a lei e a justiça é vivenciada de forma muito semelhante em relação à maneira como são representadas: são restrições que devem ser cumpridas, pois se não o forem levam a conseqüências ruins para o indivíduo. Não afirmamos que os argentinos não estejam sujeitos a essas mesmas restrições; apenas que, entre eles, estas não ocupam um espaço maior na experiência cotidiana. Os resultados indicam que na vida desses jovens há espaço para a existência de outros aspectos relativos a essas instâncias, entre eles uma maior consciência dos direitos que possuem e, quem sabe, até da possibilidade de realizarem reivindicações, nas diversas instâncias da vida. È interessante notar que, diante da atual crise econômica argentina, a população não deixou de evidenciar sua capacidade reivindicatória - o que fez por meio dos inúmeros "panelaços" (manifestações organizadas ou realizadas pela oposição política e por pessoas de diferentes estratos socioeconômicos em protesto contra o governo) que resultaram na renúncia do presidente da república e na rápida alternância, no governo, de vários outros presidentes e aliados políticos.

Parece que para os jovens brasileiros a busca da autonomia ainda é mais plausível predominantemente no âmbito privado.

\section{Referências}

Assmar, E. M. L. (2000). A psicologia social e o estudo da justiça em diferentes níveis de análise. Psicologia: Reflexão e Crítica, 13(3), 497-506.

Camino, C., Moraes, R., Pereira, C., \& Cruz, L. (2000, maio). Liberdade e responsabilidade comunitária na percepção de universitários. Comunicação apresentada no VIII Simpósio Brasileiro de Pesquisa e Intercâmbio Científico da ANPEPP, Serra Negra, São Paulo.

Da Matta, R. (1987). A casa \& a rua: espaço, cidadania e morte no Brasil. Rio de Janeiro: Guanabara.

Da Matta, R. (1991). O que faz o brasil, Brasil? Rio de Janeiro: Rocco.

Doise, W. (1986). Les représentations sociales: définition d'un concept. In W. Doise \& A. Palmonari (Orgs.), L'étude des représentations sociales (pp. 8194). Paris: Delachaux \& Niestlé.

Doise, W. (1990). Les représentations sociales. In C. B. Ghiglione \& J. P. Richard (Orgs.), Traité de psychologie cognitive. Paris: Dunod. 
Doise, W. (1993). Logiques sociales dans le raisonnement. Paris: Delachaux et Niestlé.

Doise, W., \& Clémence, A. (1996). La problématique des droits humains et la psychologie sociale. Connexions - La justice: valeurs, fonctionnements, perspectives, 67, 9-27.

Doise, W., Clémence, A., De Rosa, A. S., \& Gonzalez, L. (1995). La représentation sociale des droits de l'homme: une recherche internationale sur l'étendue el les limites de l'universalité. Journal International de Psychologie, 30, 181-212.

Doise, W., Dell Ambragio, P., \& Spini, D. (1991). Psychologie sociale et droits de l'homme. Revue Internationale de Psychologie Sociale, 4(3/4), 259-277.

Doise, W., \& Herrera, M. (1994). Déclaration universelle et représentations sociales des droits de l'homme. Une étude à Genève. Revue Internacionale de Psychologie Sociale, 2, 87-117.

Emler, N., \& Ohana, J. (1992). Réponses au préjudice: représentations sociales enfantines. Bulletin de Psychologie, 45(405), 223-231.
Halman, L. (1995). Y a-t-il un déclin moral? Enquête transnationale sur la moralité dans la société contemporaine. RISS, 145.

Jovchelovitch, S. (2000). Representações sociais e esfera pública: a construção simbólica dos espaços públicos no Brasil. Petrópolis: Vozes.

Menin, M. S. (2001). Representações sociais de lei, crime e injustiça em adolescentes. Tese de livre-docência não-publicada, Faculdade de Ciências e Tecnologia, Universidade Estadual Paulista, Presidente Prudente, SP.

Moscovici, S. (1978). A representação social da psicanálise. Rio de Janeiro: Zahar. Pierre-Puysegur, M. A., \& Corroyer, D. (1987). Les représentations du sistéme pénal chez les enfants de six à dix ans. Enfance, 40(3), 215-229.

Souza, M. (1999). A experiência da lei e a lei da experiência: ensaios sobre práticas sociais e subjetividade no Brasil. Rio de Janeiro: Revan.

Zonta, C. (1997). Práticas e representações de um bairro de periferia: os elementos centrais e periféricos do campo representacional. Tese de doutorado nãopublicada, Pontifícia Universidade Católica de São Paulo, São Paulo.

1 Pesquisa financiada pela Fundação de Amparo à Pesquisa do Estado de São Paulo.

Alessandra de Morais Shimizu, doutora em Educação pela Universidade Estadual Paulista, Campus de Marília, SP, é bolsista Prodoc junto ao Programa de Pós-Graduação em Educação, Universidade Estadual Paulista, Campus de Presidente Prudente, SP. E-mail: ashimizu@flash.tv.br

Maria Suzana de Stefano Menin, doutora em Psicologia do Escolar pela Universidade de São Paulo, é livredocente em Psicologia da Educação e do Desenvolvimento e Coordenadora do Programa de Pós-Graduação em Educação, Universidade Estadual Paulista, Campus de Presidente Prudente, SP. Endereço para correspondência: Rua José Freire Sobrinho, 409 (Bairro Jequitibá); Marília, SP; CEP 17514-014. E-mail: menin@prudente.unesp.br ou menin@prudenet.com.br 